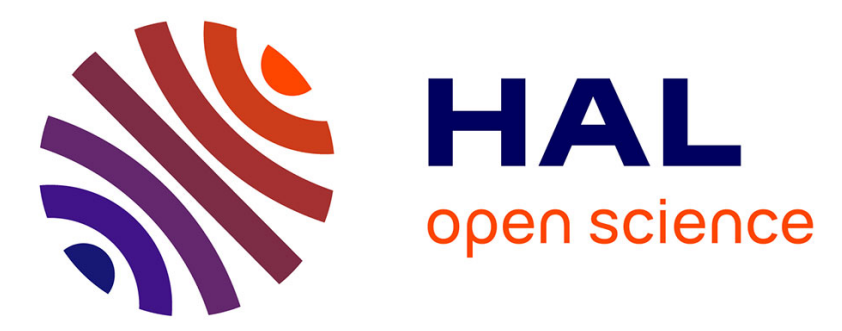

\title{
On-line gaseous formaldehyde detection by a microfluidic analytical method based on simultaneous uptake and derivatization in a temperature controlled annular flow
} Maud Guglielmino, Pierre Bernhardt, Claire Trocquet, Christophe A. Serra, Stéphane Le Calvé

\section{To cite this version:}

Maud Guglielmino, Pierre Bernhardt, Claire Trocquet, Christophe A. Serra, Stéphane Le Calvé. Online gaseous formaldehyde detection by a microfluidic analytical method based on simultaneous uptake and derivatization in a temperature controlled annular flow. Talanta, 2017, 172, pp.102-108. 10.1016/j.talanta.2017.05.038 . hal-02273445

\section{HAL Id: hal-02273445 \\ https://hal.science/hal-02273445}

Submitted on 21 Dec 2020

HAL is a multi-disciplinary open access archive for the deposit and dissemination of scientific research documents, whether they are published or not. The documents may come from teaching and research institutions in France or abroad, or from public or private research centers.
L'archive ouverte pluridisciplinaire HAL, est destinée au dépôt et à la diffusion de documents scientifiques de niveau recherche, publiés ou non, émanant des établissements d'enseignement et de recherche français ou étrangers, des laboratoires publics ou privés. 
1 On-line gaseous formaldehyde detection by a microfluidic analytical method based on simultaneous uptake and derivatization in a temperature controlled annular flow

Maud Guglielmino ${ }^{a, b}$, Pierre Bernhardt ${ }^{a, c}$, Claire Trocquet $^{a, c}$, Christophe A. Serra $^{b}$, Stéphane Le Calvéa, c 1

${ }^{a}$ Institut de Chimie et Procédé pour l'Energie, l'Environnement et la Santé (ICPEES, UMR 7515 CNRS/UdS), group of atmospheric physical chemistry, 25 rue Becquerel, 67087 Strasbourg Cedex 02, France.

b Université de Strasbourg, CNRS, ICS UPR 22, F-67000 Strasbourg, France.

' In'Air Solutions, 1 rue Blessig 67000 Strasbourg France.

\section{Highlights}

- Intensified analytical microdevice for quantification of gaseous formaldehyde

- Gaseous formaldehyde uptake through the establishment of a microfluidic annular flow

- Derivatization reaction of formaldehyde with acetylacetone at $65^{\circ} \mathrm{C}$

- Formaldehyde detection by means of a colorimetric cell based on a liquid core waveguide

\section{Abstract}

This paper is focused on the improvement of a microfluidic analytical method for the detection of low airborne formaldehyde concentrations, based on only two distinct steps permitting to reduce the response time and to improve the compactness of the device. First, gaseous formaldehyde is trapped into an acetylacetone solution at $65^{\circ} \mathrm{C}$ through an annular liquid/gas flow and reacts immediately to form 3,5-Diacetyl-1,4-dihydrolutidine which is then quantified by colorimetry using a liquid core waveguide (LCW).

To obtain an annular flow, 3 different hydrophilic silica capillaries of 320, 450 and $530 \mu \mathrm{m}$ ID were tested and the corresponding phase diagrams were obtained in the ranges of liquid and gas flows of

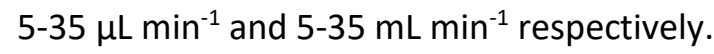

Finally, the analytical performances were determined using the lowest flow values of $5 \mu \mathrm{L} . \mathrm{min}^{-1}$ and 5 $\mathrm{NmL}$. $\mathrm{min}^{-1}$, ensuring an annular flow and increasing the microdevice autonomy. If the uptake yield of gaseous formaldehyde into the solution was close to $100 \%$, only the $530 \mu \mathrm{m}$ ID capillary permits to obtain a reaction time long enough for a full conversion of formaldehyde into 3,5-Diacetyl-1,4dihydrolutidine. With a LCW pathlength of $5 \mathrm{~cm}$, the microdevice response was perfectly linear in the range $0-154 \mu \mathrm{g} \mathrm{m}^{-3}$ with a detection limit of $1.8 \mu \mathrm{g} \mathrm{m}^{-3}$.

1 Corresponding author at: Institut de Chimie et Procédé pour l'Energie, I'Environnement et la Santé (ICPEES, UMR 7515 CNRS/UdS) Groupe physico-chimie de l'atmosphère, 25 rue Becquerel 67087 Strasbourg Cedex 0, France Tel. :+33 3688503 68. E-mail address: slecalve@unistra.fr. 
Keywords: Formaldehyde, microfluidics, annular flow, microdevice, indoor air 36 


\section{Introduction}

Formaldehyde is a major pollutant of indoor air due to its multiple sources (materials, combustion, painting, etc.). Several studies [1-3] have shown that indoor formaldehyde concentrations are 2 to 15 times higher than those measured outdoor, and may vary typically between 10 to $100 \mu \mathrm{g} \mathrm{m}^{-3}$. Casset et al. (2006) have shown that formaldehyde is implicated in allergic diseases, particularly for asthmatic people [4]. Starting from 2004, formaldehyde is considered as a carcinogenic compound for human by the International Agency for Research on Cancer [5]. French recommendations aim at limiting formaldehyde concentrations in public buildings to $30 \mu \mathrm{g} \mathrm{m}^{-3}$ by 2018. Therefore, sensitive methods and potentially transportable or highly portable instruments capable of monitoring airborne formaldehyde concentration are highly required.

The main analytical methods used for quantification of airborne formaldehyde concentrations are summarized in Table 1. The conventional and reference method [6-9] uses an active or passive sampling on 2,4-Dinitrophenylhydrazine (DNPH) cartridge for several hours or several days respectively, followed by an HPLC/UV visible analysis which is time-consuming and involves a laboratory treatment with bulky instruments. In addition, this approach does not provide real-time results and only gives an average value of concentration.

Many alternative methods oriented towards real-time and in-field detection, have been developed such as Hantzsch monitor [10-11], Proton-Transfer-Reaction Mass Spectrometry (PTR-MS) [12-13], GCMS [14], infrared diode laser spectroscopy [9]. However most of these methods rely on bulky apparatus and then are not adapted for indoor air monitoring where portability is a key point (see Table 1). Among the methods which were developed, some used specific reagents that can react with formaldehyde to produce a compound which can be detected either by colorimetry or fluorescence [10, 15-18]. Miniature and portable systems based on color change in solid materials, which is conveniently used for the detection, have been developed [19-20]. Nevertheless, autonomic and fully continuous monitoring was not possible since with time the solid detection element got saturated and could not be renewed. In addition, the resolution of such sensors was usually not as good as needed to detect the very low formaldehyde concentrations recommended by the state legislation.

Another type of transportable instrument, based on the uptake and concentration of formaldehyde into an aqueous solution followed by the derivatization reaction at $60-80^{\circ} \mathrm{C}$ and the fluorescence detection, has also been developed in our laboratory [20-21]. Such very sensitive analytical instrument with detection limit lower than $0.5 \mathrm{\mu g} \mathrm{m}^{-3}$ is considered to be transportable and real-time due to its low weight $(8 \mathrm{~kg})$ and its time resolution (10 minutes). However, its high liquid reagent consumption of $1.1 \mathrm{~mL} \mathrm{~min}{ }^{-1}$ does not provide sufficient autonomy since $100 \mathrm{~mL}$ can permit only $1 \mathrm{~h} 40$ operation time and 10 measurements. In addition, more miniaturization is needed for in-field monitoring.

Gas/liquid flows in large channels have been studied intensively owing to the numerous applications such as mass bubble column reactors [22] or mass transport in pipes [23]. Different flow patterns (e.g. bubbly, stratified, slug, annular, churn etc.) were reported as a function of fluid properties (mainly viscosity and density), liquid and gas phase velocity or pipes dimensions and tilt. In large channel gravity and inertial forces are predominant while in microchannels, like capillary tubes, surface tension and viscous force play a dominant role; thus transitions between the different flow patterns are no longer the same as in case of large channels. Many authors [24-29] have reported that in such tiny environment stratified flows were never observed. Triplett et al. (1999) studied the air-water two- 
phase flow at $25^{\circ} \mathrm{C}$ in a $1.1 \mathrm{~mm}$ ID capillary and observed that the bubbly pattern is obtained when the liquid flow rate is much greater that the air flow rate. When the former is of same order but still greater that the latter, the slug pattern is observed [30]. Then the churn, slug-annular and annular patterns are obtained when the gas flow rate is increased, when the gas to air flow rate ratio reaches 100 and for further higher gas flow rates respectively. Chung and Kuwaji (2004) studied the two-phase flow of nitrogen and water at a temperature no higher than $30^{\circ} \mathrm{C}$ in 250 and $530 \mu \mathrm{m}$ ID capillaries [31]. They found that all flow patterns seen by Triplett et al. (1999) [30] were also present in both capillaries [31].

The overall goal of our work is then to develop a formaldehyde analytical method which combines precision, selectivity and fast analysis in a single portable miniaturized instrument which will be more suitable for field measurement with reagent autonomy sufficient for a two weeks continuous monitoring. The work reported in this paper aimed at improving the existing microfluidic system described in a previous publication [32] and which was based on a microfluidic device operating in 3 combined steps, i.e. gaseous formaldehyde uptake into the aqueous solution using an annular gas/liquid flow at room temperature, the derivatization reaction with acetylacetone at $65^{\circ} \mathrm{C}$ and finally 3,5-Diacetyl-1,4-dihydrolutidine (DDL) detection by colorimetry by means of a Liquid Wave Core (LCW) of $44 \mathrm{~cm}$ length and $207 \mu \mathrm{m}$ ID [32]. More precisely, since the configuration of the annular flow allows a residence time potentially long enough to convert totally formaldehyde into DDL in liquid phase, the first objective was to couple the uptake and reaction steps at $65^{\circ} \mathrm{C}$ in a single step to reduce the response time of the analytical instrument. As such we will investigate the liquid/gas phase diagram in capillary of different dimensions at high temperature which was to the best of our knowledge scarcely reported in the literature. The second objective was to reduce the reactant consumption of $35 \mu \mathrm{L} \mathrm{min}$ ${ }^{1}$ previously reported [32] and therefore increase the microdevice autonomy.

\section{Materials and method}

\subsection{Chemicals}

The reaction between acetylacetone solution (Fluoral-P) and formaldehyde producing DDL was first investigated via a Hantszch reaction [33] in details. Acetylacetone solution (0.01 M) was prepared by mixing $0.3 \mathrm{~mL}$ of acetic acid (100\%, Merck), $0.2 \mathrm{~mL}$ of acetylacetone (99\%, Merck), $15.4 \mathrm{~g}$ of ammonium acetate (98\%, Sigma-Aldrich) in $200 \mathrm{~mL}$ Milli-Q water (18.2 M $\Omega . \mathrm{cm}$ at $25^{\circ} \mathrm{C}$, Millipore). The reagent bottle was equipped with a DNPH cartridge to purify the air entering the vial so as to avoid any contamination of the reagent with formaldehyde present in the ambient air.

Gaseous formaldehyde mixtures, whose concentration was varied from 0 to $154.4 \mu \mathrm{g} \mathrm{m}^{-3}$ ( 0 to $5.1 \times 10^{-}$

${ }^{6} \mathrm{M}$ once quantitatively transferred into the liquid phase), were prepared by means of a homemade gaseous formaldehyde source whose development and optimization was reported in a previous work [21]. Briefly, this source generates gaseous formaldehyde by applying a controlled gas flow $(5-20 \mathrm{NmL}$ $\mathrm{min}^{-1}$ ) in a microporous tube immersed in a concentrated formaldehyde solution of $0.0925 \%$ regulated at $10^{\circ} \mathrm{C}$ by a Peltier module. This enriched gaseous formaldehyde stream is then diluted with a controlled flow (500-2000 NmL min ${ }^{-1}$, Messer) of pure air (>99.999\%, total VOCs $<50 \mathrm{ppb}, \mathrm{HCHO}<1$ $\mathrm{ppb})$. The concentrated formaldehyde solution of $0.0925 \%$ was prepared by mixing a commercial formaldehyde solution ( $37 \%$ in water, Sigma-Aldrich) with Milli-Q water $\left(18.2 \mathrm{M} \Omega . \mathrm{cm}\right.$ at $25^{\circ} \mathrm{C}$, Millipore). Finally, the generated gaseous formaldehyde concentrations were precisely quantified using the conventional sampling method on DNPH cartridges followed by HPLC/UV analysis already described elsewhere $[6,34]$. The overall relative uncertainties on the measured gaseous 
concentrations were in the range $8-12 \%$ and were calculated from uncertainties of flow meters of the formaldehyde source, the gas sampling and HPLC analysis of DNPH cartridges.

For liquid calibration, formaldehyde solutions in the range $0-207.6 \mu \mathrm{g} \mathrm{L}^{-1}\left(0-10.210^{-6} \mathrm{M}\right)$ were prepared by mixing a commercial formaldehyde solution (37\% in water, Sigma-Aldrich) with Milli-Q water $\left(18.2 \mathrm{M} \Omega . \mathrm{cm}\right.$ at $25^{\circ} \mathrm{C}$, Millipore). They were subsequently diluted by half in a solution of acetylacetone $0.02 \mathrm{M}$ to directly obtain formaldehyde concentrations ranging from 0 to $153.8 \mu \mathrm{g} \mathrm{L}^{-1}(0$ to $5.110^{-6} \mathrm{M}$ ) in a solution of acetylacetone $0.01 \mathrm{M}$.

\subsection{Setups and experimental conditions}

\subsubsection{Overall setup for detection of gaseous formaldehyde}

The setup used for the quantification of gaseous formaldehyde is represented in Figure 1. It consisted in three sequential steps: 1) fluid feeding lines, 2) gaseous formaldehyde uptake into the aqueous solution using an annular gas/liquid flow at $65^{\circ} \mathrm{C}$ and simultaneously derivatization reaction with acetylacetone at $65^{\circ} \mathrm{C}$ and finally 3) DDL detection by colorimetry.

The aqueous solution of acetylacetone $(0.01 \mathrm{M})$ was pumped at a flowrate of $5 \mu \mathrm{L} \mathrm{min}^{-1}$ thanks to a peristaltic pump (Ismatec, Reglo Lab) while a gas pump (NMP 850 KTDC, KNF) and a gas flow controller (low $\Delta \mathrm{P}$ flow, 0-100 NmL.min ${ }^{-1}$, Bronkhorst) ensured the constant flow rate $\left(5 \mathrm{NmL} \mathrm{min}{ }^{-1}\right.$ ) of the gaseous formaldehyde mixture. The uptake arrangement was composed of a $1 / 16^{\prime \prime}$ PEEK T-junction (P728-01; Upchurch) paired with two hydrophilic fused co-axial silica capillaries (Polymicro). The gas mixture flowed through the inner capillary (100 $\mu \mathrm{m}$ ID $\times 150 \mu \mathrm{m}$ OD) while the gas/liquid flow exited the T-junction through the outer capillary whose size was varied $(320,430$ or $530 \mu \mathrm{m}$ ID $\times 420,550$ or $680 \mu \mathrm{m} \mathrm{OD}$ ). The gas flow rate was thus 3 orders of magnitudes higher that the liquid flow rate which under a specific flow rates ratio gave rise (cf. §3.1) to the formation of an annular flow as illustrated in the inset of Figure 1. Due to a very high Henry's law constant of $5020 \mathrm{M} \mathrm{atm}^{-1}$ [35] and a large interface area between gas and liquid phases promoted by the annular flow, the formaldehyde was transferred from the gas to the liquid phase. Both uptake of gaseous formaldehyde and derivative steps occurred simultaneously at $65^{\circ} \mathrm{C}$ in order to reduce the response time compared to two sequential steps as reported in our previous work [32]. Furthermore, it also allows increasing the compactness of the setup. Finally, operating at $65^{\circ} \mathrm{C}$ speeds up the conversion of formaldehyde to DDL for reproducible quantification of formaldehyde.

The gas was removed in flow by means of a microporous tube $(\mu \mathrm{PT})$ and the resulting gas-free liquid phase containing the DDL was transferred to the colorimetric cell through a $250 \mu \mathrm{m} I D \times 1 / 16$ " OD PEEK capillary. This cell was composed of 4 different parts (cf. Figure 1): i) a Liquid-Core-Waveguide (LCW, BioGeneral), $400 \mu \mathrm{m}$ ID and $5 \mathrm{~cm}$ length, with an inner coating of Teflon ${ }^{\circledR}$ AF 2400 allowing the light to travel through the liquid solution by total reflection, the LCW was wrapped in an aluminum foil to avoid any external parasite light; ii) 2 homemade one-inlet/two-outlet connectors with low dead volume and made of black polymeric material to avoid any parasite light; one port of both T-connector was used to connect the LCW, another port was used for the inlet and outlet (waste) of the DDL solution, finally the last port was used for a SMA adapter to connect in a straight manner the $1500 \mu \mathrm{m}$ optical fibers (IDIL Fibres Optiques); iii) a Deuterium-halogen light source (DH-2000, Ocean Optics) and iv) a minispectrometer (C10082CAH, Hamamatsu).

\subsubsection{Setup for gas/liquid phase diagram determination}


To determine the flow pattern of the gas/liquid flow inside the outer capillary at $65^{\circ} \mathrm{C}$, the setup represented in Figure 2 was used. A syringe pump (Phd 2000, Harvard Apparatus) was used to pump a fresh acetylacetone solution ( $0.01 \mathrm{M})$ through a TEFLON tubing (300 $\mu \mathrm{m}$ ID $\left.\times 1 / 16^{\prime \prime} \mathrm{OD}\right)$. Another syringe pump was used to inject air through another TEFLON tubing ( $810 \mu \mathrm{m}$ ID $\times 1 / 16^{\prime \prime} \mathrm{OD}$ ). Then the two fluids entered a temperature controlled oven, the lengths of both tubings were set to $25 \mathrm{~cm}$ and $110 \mathrm{~cm}$ respectively to insure a residence time long enough so that the fluids reached $65^{\circ} \mathrm{C}$ at the oven's exit. Then they flowed through the same aforementioned uptake arrangement detailed in the inset of Figure 1 for which the same three capillaries were investigated (320, 430 or $530 \mu \mathrm{m}$ ID $\times 420$, 550 or $680 \mu \mathrm{m}$ OD). $10 \mathrm{~cm}$ downstream to the T-junction, an optical microscope (Eclipse TS 100, Nikon) was placed above the outer capillary to take pictures and record the flow pattern thanks to a CCD camera (PIKE F-032C, Allied Technology) and an imaging software (Hiris, R\&D Vision). Thus to determine the flow pattern inside the outer capillary, the liquid flow rate was varied from 5 to $35 \mu \mathrm{L}$ $\mathrm{min}^{-1}$ while the gas flow rate was varied from 5 to $35 \mathrm{~mL} \mathrm{~min}^{-1}$. Since the gas flow rates are quite low, the compressible effect can be neglected, the Mach number at $65^{\circ} \mathrm{C}$ was calculated to be equal to $6 \%$. Thus all the gas flow rates reported for the phase diagrams are expressed as the flow rate induced by the syringe pump at $20^{\circ} \mathrm{C}$ (room temperature). Upon modification of an operating parameter, at least $10 \mathrm{~min}$ were elapsed before to record the flow pattern such as the new steady state was reached.

\subsubsection{Setup and experimental conditions for the gaseous or aqueous formaldehyde calibration}

The length of the uptake cell was $150 \mathrm{~cm}$ whereas the internal diameter and length of the colorimetric detection cell were $400 \mu \mathrm{m}$ and $5 \mathrm{~cm}$, respectively. The liquid and gas flow rate were fixed to $5 \mu \mathrm{L} \mathrm{min}$ ${ }^{1}$ and $5 \mathrm{NmL} \mathrm{min}^{-1}$, respectively. In order to evaluate the uptake yield, both gas and liquid calibrations were then performed using the setup detailed in Figure 1.

In fact, the experimental apparatus for carrying out liquid phase formaldehyde calibration is similar to the one used for the calibration of the concentrations of gaseous formaldehyde. The only two differences are as follows: 1) synthetic air free of formaldehyde replaces the gaseous formaldehyde mixtures to keep exactly the same residence time in the uptake cell and 2) acetylacetone solution 0.01 $M$ is replaced by a mixture of acetylacetone doped with a known concentration of formaldehyde prepared as detailed in section 2.1.

\section{Results and discussion}

\subsection{Gas/Liquid phase diagram}

To determine the combination of gas and liquid flow rates that provide an annular flow, the acetylacetone/air phase diagram was determined experimentally following the procedure described in section 2.2.2. Depending of the flow rates of both liquid and gas phases, up to 4 different flow patterns were observed, namely slug, slug-annular, annular and chaotic flows as illustrated in Figure S1. The phase diagram for the $530 \mu \mathrm{m}$ ID outer capillary at $65^{\circ} \mathrm{C}$ is presented in Figure 3 while results for the two other capillaries (430 and $320 \mu \mathrm{m}$ ID) are reported in Figure S2A\&B respectively.

Whatever the capillary ID, the slug patterns were found in the top left part of the phase diagram, i.e. when the gas flow rate was low and liquid flow rate was high. When the gas flow rate was increased, an intermediate region appeared and the flow adopted a slug-annular pattern. Finally when the gas to 
liquid flow rate ratio was around or greater than 1,000, a large annular region covered the whole right hand part of the phase diagram. However for the highest capillary ID $(530 \mu \mathrm{m})$ a chaotic pattern was observed in the bottom right corner of the phase diagram, i.e. for the lowest liquid flow rates and the highest gas flow rates conversely to the two other capillary dimensions (Figure S2A\&B). Compared to the work of Chung and Kuwaji (2004) conducted with nitrogen and air at temperatures ranging from 22.9 to $29.9^{\circ} \mathrm{C}$ in a $530 \mu \mathrm{m}$ ID capillary [36], we did not observed the bubbly and churn pattern just because we kept the liquid flow rate quite low in order to increase the autonomy of our analytical microdevice, the maximum gas and liquid flow rates were set to $35 \mathrm{~mL} \mathrm{~min}{ }^{-1}$ and $35 \mu \mathrm{L} \mathrm{min}{ }^{-1}$ respectively.

In a previous paper [32], we investigated the flow pattern for an outer capillary of $530 \mu \mathrm{m} I D \times 680 \mu \mathrm{m}$ $\mathrm{OD}$ at $23^{\circ} \mathrm{C}$. Effect of temperature $\left(23^{\circ} \mathrm{C}\right.$ vs. $\left.65^{\circ} \mathrm{C}\right)$ on the transition lines between the different flow patterns is presented in Figure S3. It is observed that when the temperature increases, the transition between slug-annular and annular patterns is shifted toward lower gas and higher liquid flow rates. Same observation can also been drawn for the transition between slug and slug-annular patterns. Finally, the phase diagram at $65^{\circ} \mathrm{C}$ exhibits a chaotic pattern which is not present in the phase diagram at $23^{\circ} \mathrm{C}$. These observations can be explained by the change in viscosity of the liquid and gas when the temperature increases from $23^{\circ} \mathrm{C}$ to $65^{\circ} \mathrm{C}$ (Table S1). While the viscosity of liquid decreases by $57 \%$, the viscosity of the gas is increasing by $13 \%$. As a consequence, the slug-annular flow is shifted to the left hand part of the diagram as the gas is exerting on the liquid a higher shear force resulting in the draining of the liquid film along the wall of the capillary. Thus, the annular region is expanding. For the same reason, the transition between slug and slug-annular is also shifted toward the left hand part of the diagram, therefore the slug region is reducing. Appearance of the chaotic region in the bottom right region of the phase diagram at $65^{\circ} \mathrm{C}$ may result from the combined effect of high gas flow rates and increased gas viscosity which at some point disturbs the liquid film flowing along the wall of the capillary (see figure S1).

Thus, operating at $65^{\circ} \mathrm{C}$ still allows working in an annular flow regime for the same range of liquid and gas flow rates as for $23^{\circ} \mathrm{C}$ but gives the opportunity to promote a faster derivatization reaction and to reduce the analytical response time.

\subsection{Influence of the capillary ID on the uptake efficiency}

The effect of the capillary ID used in the uptake cell was studied using successively capillaries of different internal diameters (320, 430 and $530 \mu \mathrm{m})$ using the same experimental conditions defined in section 2.2.3. For each capillary, both gas and liquid calibrations were conducted in order to determine the uptake yield of gaseous formaldehyde into the solution (see section 3.5).

\subsection{Gaseous formaldehyde calibration}

The calibration of the absorbance as a function of the concentration signal was performed for each uptake capillary cell, i.e. 320, 430 and $530 \mu \mathrm{m}$ ID. Figure 4 shows that the absorbance signal increases linearly $\left(0.995<R^{2}<0.998\right)$ when the concentration of gaseous formaldehyde increases from 0 to 154.4 $\mu \mathrm{g} \mathrm{m}^{-3}\left(0\right.$ to $\left.5.1 \times 10^{-6} \mathrm{M}\right)$ whatever the capillary ID. The absorbance uncertainties were estimated to be the standard deviation calculated from 3 or 4 consecutive measurements and varied between 3 and $6.5 \%$. They correspond to the overall analytical system including the gaseous formaldehyde generation and the analytical instrument itself. In addition, Figure 4 shows that the higher the capillary ID, the higher is the slope, from $2.47 \times 10^{4} \mathrm{M}^{-1}$ for $320 \mu \mathrm{m}$ ID to $3.60 \times 10^{4} \mathrm{M}^{-1}$ for $530 \mu \mathrm{m}$ ID. These results may 
suggest that uptake yield could increase with the capillary ID. In order to subsequently determine the effective uptake efficiency, the main abscissa of the figure 4 corresponds to the theoretical aqueous formaldehyde concentration trapped (in units of $\mathrm{mol} \mathrm{L}^{-1}$ ) in the case of a full uptake from gas phase.

\subsection{Liquid formaldehyde calibration}

As observed for the gaseous formaldehyde calibration, Figure 5 shows that the absorbance increases linearly $\left(0.994<R^{2}<0.996\right)$ when the liquid formaldehyde concentration increases from 0 to $153.8 \mu \mathrm{g} \mathrm{L}^{-1}$ ( 0 to $5.1 \times 10^{-6}$ to $\mathrm{M}$ ). The standard deviation calculated from 3 or 4 consecutive measurements ranged between 2 and $5 \%$.

Similarly to the gaseous formaldehyde calibration curves shown in Figure 4, the higher slope is obtained for the highest capillary ID (see Figure 5). According to the Beer Lambert law and considering a $5 \mathrm{~cm}$ pathlength, the slope can be used to extract the molar extinction coefficient $\varepsilon$ of DDL. In our case, the $\varepsilon$ values are the following: $4176 \pm 406 \mathrm{M}^{-1} \mathrm{~cm}^{-1}$ for $320 \mu \mathrm{m} \mathrm{ID,} 5120 \pm 430 \mathrm{M}^{-1} \mathrm{~cm}^{-1}$ for 430 $\mu \mathrm{m}$ ID and $7216 \pm 611 \mathrm{M}^{-1} \mathrm{~cm}^{-1}$ for $530 \mu \mathrm{m}$ ID. The latter value is consistent with that determined from our previous work using a colorimetric cell LCW of $207 \mu \mathrm{m}$ ID and $44 \mathrm{~cm}$ length $\left(\varepsilon=7320 \pm 610 \mathrm{M}^{-1} \mathrm{~cm}^{-}\right.$ ${ }^{1}$ [32] and in good agreement with the literature data $\left(\varepsilon=7500 \mathrm{M}^{-1} \mathrm{~cm}^{-1}\right.$ [11]). These results suggest therefore that the residence time and consequently the reaction time inside the capillary uptake cell permits a full conversion of formaldehyde into DDL for a $530 \mu \mathrm{m}$ capillary ID but it is not sufficient for both $320 \mu \mathrm{m}$ and $430 \mu \mathrm{m}$ capillary IDs.

Indeed, in an annular flow, the thickness of the liquid film decreases with the decrease of the internal diameter of the capillary [37]. For a fixed liquid flow rate (here $5 \mu \mathrm{L} \mathrm{min}^{-1}$ ) and a given cell length (here $150 \mathrm{~cm}$ ), this implies an increase in the liquid linear velocity and thus a shorter residence time of the liquid. Therefore, it is more relevant to use the biggest capillary.

\subsection{Uptake yield}

The joint gaseous and liquid formaldehyde calibrations allow the determination of the uptake yield for the 3 investigated uptake cells characterized by their capillary ID. The uptake yield is defined as the ratio between the gaseous calibration slope multiplied by 100 and the liquid calibration slope obtained in the same experimental conditions, i.e. the same liquid and gas flow rates. The formaldehyde uptake yields obtained are the following: $118 \pm 22 \%$ (320 $\mu \mathrm{m}$ ID), $107 \pm 18 \%$ (430 $\mu \mathrm{m}$ ID) and $100 \pm 16 \%$ (530 $\mu \mathrm{m}$ ID) where the uncertainties are calculated from the uncertainties slopes $(2 \sigma)$. This shows that whatever the capillary ID used, the uptake efficiency should be total with an annular flow, or at least almost total if we consider the errors bars.

\subsection{Analytical performances}

As demonstrated above with the determination of $\varepsilon$, it appears that the derivatization reaction of formaldehyde to DDL is only complete for a capillary with an inner diameter of $530 \mu \mathrm{m}$. Consequently, the analytical performances of the device described in section 2.2.1 were evaluated for an uptake capillary of $530 \mu \mathrm{m} I D$ and $150 \mathrm{~cm}$ long, a colorimetric cell made of $5 \mathrm{~cm} \mathrm{LCW}$ using liquid and gas flows

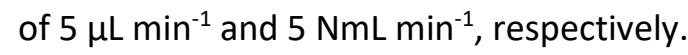

\subsubsection{Linearity range, detection and quantification limits}


The gas calibration curve, shown in Figure 4, demonstrates that the response of the new analytical method is linear $\left(R^{2}=0.998\right)$ for gaseous formaldehyde concentrations ranging from 0 to $154 \mu \mathrm{g} \mathrm{m}^{-3}(0$ to $5.110^{-6} \mathrm{M}$ ) which corresponds to typical concentrations found in indoor air.

The gas calibration curve was used to determine both limit of detection (LOD) and limit of quantification (LOQ) of the device in the gas phase. From the lowest formaldehyde concentration investigated, i.e. about $20 \mu \mathrm{g} \mathrm{m}^{-3}$, the detection and quantification limits were estimated to be $1.8 \mu \mathrm{g}$ $\mathrm{m}^{-3}(\mathrm{~S} / \mathrm{N}=3)$ and $6.1 \mu \mathrm{g} \mathrm{m}^{-3}(\mathrm{~S} / \mathrm{N}=10)$, respectively.

\subsubsection{Repeatability and reproducibility}

For both repeatability and reproducibility measurements, the zero of the measurement was performed every 6 hours to prevent any slight baseline drift due to the possible reagent contamination or slight drift of the UV lamp energy.

A series of 10 measurements was performed using the analytical method developed above and under the optimum conditions determined previously, i.e. $5 \mu \mathrm{L} \mathrm{min}^{-1}$ and $5 \mathrm{NmL} \mathrm{min}{ }^{-1}$ for liquid and gas flow rates respectively, with the same operator using the same sample. The formaldehyde concentration generated by the source was $51.7 \mathrm{\mu g} \mathrm{m}^{-3}$. The corresponding results are shown in Figure 6. From these 10 measurements, the Relative Standard Deviation (RSD) is determined equal to $2.7 \%$. This value, less than $5 \%$, means that the repeatability of this novel analytical method is extremely satisfactory.

3 series of 5 measurements each covering one full week were then conducted, with the same operator using the same gas formaldehyde concentration, on three different days. The results are shown in Figure S4. The RSD determined from all of these measurements is equal to $3.6 \%$. As for repeatability, this RSD value being less than $5 \%$ demonstrates the very good reproducibility of the new microfluidic analytical method.

\subsubsection{Comparison with available techniques}

The analytical performances of our prototype have been compared in Table 1 with those reported in the literature [9-10,12,14-16, 18, 38-39] for other methods and apparatus, in terms of limit of detection, time resolution, possible interferences, liquid reagent consumptions when it was relevant and weight as a portability indicator. All the chromatographic and spectroscopic methods have been already discussed in the introduction. In addition, they cannot be considered as neither transportable nor portable so that no more comparison is given here.

Among the chemical methods which are potentially portable or at least transportable, the colorimetric microfluidic device developed in this work appears to be the most portable regarding its weight and the most autonomous considering its very low liquid reagent consumption of $5 \mu \mathrm{L} \mathrm{min}{ }^{-1}$. In addition, the use of only one reagent makes it simpler for operation. Its time resolution of 1-2 minutes and its sensitivity of $1.8 \mu \mathrm{g} \cdot \mathrm{m}^{-3}$ permit to rapidly monitor changes in formaldehyde concentration in air and allow accurate measurements below the threshold value of $30 \mu \mathrm{g} \mathrm{m}^{-3}$.

\section{Conclusions}

Gas/liquid phase diagrams at $65^{\circ} \mathrm{C}$ for liquid and gas flow rates ranging from 5 to $35 \mu \mathrm{L} \mathrm{min}^{-1}$ and from 5 to $35 \mathrm{~mL} \mathrm{~min}{ }^{-1}$ respectively were experimentally drawn for different capillary IDs (320, 430 and 530 
$\mu \mathrm{m})$ and revealed up to four different flow patterns: slug, slug-annular, annular and chaotic. This latter pattern was only found for the highest gas flow rates investigated in the $530 \mu \mathrm{m}$ ID capillary. Compare to similar work carried out on nitrogen-water two-phase flow in a $530 \mu \mathrm{m}$ ID capillary, absence of bubbly and churn patterns results from the extremely low liquid flow rate we used so as to maximize our microdevice autonomy. In our system, the annular flow pattern was obtained for gas to liquid flow rate ratio around or greater than 1,000. As such we have identify the lowest eligible flow rates to obtain an annular flow and reduce the reagent consumption, i.e. liquid and gas flow rates of $5 \mu \mathrm{L} \mathrm{min}{ }^{-1}$ and 5 $\mathrm{NmL} \mathrm{min}^{-1}$ respectively.

In addition, both liquid and gaseous calibration curves showed a linear response of the analytical method regardless of the capillary ID for formaldehyde concentrations representative of those found in indoor air. However, the derivatization reaction was complete only for a $530 \mu \mathrm{m}$ capillary ID, the capillary length being not long enough for the other tested capillaries.

Using the $530 \mu \mathrm{m}$ capillary ID, the detection and quantification limits were then estimated to 1.8 and $6.1 \mu \mathrm{g} \mathrm{m}^{-3}$ respectively for a LCW pathlength of $5 \mathrm{~cm}$. From a purely analytical point of view, a longer acquisition time of the spectrometer could permit to reduce the noise and consequently to improve the LOD and LOQ. Another possibility could consist in increasing the pathlength for example from 5 to $20 \mathrm{~cm}$.

However, the current LOD of this novel microdevice is sufficient enough to achieve quantitative measurements in indoor air to meet the regulation which fixes a threshold value of $30 \mu \mathrm{g} \mathrm{m}^{-3}$ by 2018 . These results are very promising and could still be improved in the near future by using the fluorescence detection of DDL as previously reported by Le Calvé et al. (2012) [21].

The use of this new device achieves both objectives, namely a shorter response time and greater autonomy. The acetylacetone consumption was reduced by a factor of 10 compared to the previous device since the liquid flow rate decreased from 35 to $5 \mu \mathrm{L} \mathrm{min}{ }^{-1}$. For a given flow rate of $5 \mu \mathrm{L} \mathrm{min}{ }^{-1}$, the gain in response time was estimated about 4 minutes, i.e. the time required for ensuring full conversion of formaldehyde to DDL in the oven ( 3 minutes) and for passing through an additional microporous tube placed after the oven ( 1 minute), the new response time being estimated to 6 minutes. The corresponding autonomy with $100 \mathrm{~mL}$ of acetylacetone solutions is estimated to 13.9 days which is significantly longer than those obtained in previous works, i.e. 2.0 days [32] or 1.7 hours [21].

Finally, the development performed in this work has contributed to obtain a highly portable formaldehyde microanalyser weighting less than $4 \mathrm{~kg}$ and having an autonomy of two weeks with an acetylacetone reservoir of $100 \mathrm{~mL}$ for a continuous monitoring.

\section{Acknowledgement}

This work was supported by ADEME and Region Alsace, REALISE, the program PRIMEQUAL and ANR (ANR-11-ECOT-0013).

\section{References}

[1] B. Wang, S.C. Lee and K.F. Ho, Atmos. Environ., 41 (2007) 2851-2861.

[2] X. Wang, H. Wang and S. Wang, Atmos. Environ., 44 (2010) 2074-2078.

[3] N.L. Gilbert, Guay M. and D. et al Gauvin, Atmos.Environ., 42 (2008) 1336-1345. 
[4] A. Casset, C. Marchand, A. Purohit, S. Le Calvé, C. Donnay, P. Meyer, G. Pauli and F. de Blay, J. of Allergy and Clinical Immunology, S23 (2006) 117.

[5] IARC, International Agency for Research on Cancer, (2004) [50-00-0].

[6] C. Marchand, S. Le Calvé, Ph. Mirabel, Glasser N., A. Casset, N. Schneider and de Blay F., Atmos. Environ., 42 (2008) 505-516.

[7] R.M. Cerón, J.G. Cerón and M. Muriel, Atmos. Environ., 41 (2007) 63-71.

[8] T. Wangchuk, C. He, M.R. Dudzinska and L. Morawska, Atmos. Environ., 113 (2015) 151-158.

[9] B. Hanoune, T. Le Bris, L. Allou, C. Marchand and S. Le Calvé, Atmos. Environ, 40 (2006) 57685775.

[10] C. Hak, I. Pundt, S. Trick, C. Kern and U. Platt, Atmos. Chem. Phys., 5 (2005) 2881-2900.

[11] T. Salthammer, J. Photochem. Photobiol. A: Chem., 74 (1993) 195-201.

[12] A. Wisthaler, E.C. Apel, J. Bossmeyer, A. Hansel, W. Junkermann and R. Koppmann, Atmospheric Chem. Phys., 8 (2008) 2189-2200.

[13] A. Vlasenko, A. M. Macdonald, S. J. Sjostedt and J. P. D. Abbatt, Atmos. Meas. Tech., 3 (2010) 1055-1062.

[14] R. Bono, R. Degan, M. Pazzi, V. Romanazzi and R. Rovere, Environ. Int., 36 (2010) 269-275.

[15] W. Zheng, Développement d'un analyseur rapide et transportable du formaldéhyde dans l'air, PhD thesis in Chemistry. 2010, Université de Strasbourg: Strasbourg.

[16] T. Sakai, S. Tanaka, N. Teshima, S. Yasuda and N. Ura, Talanta, 58 (2002) 1271-1278.

[17] J. Li, P.K. Dasgupta, Z. Genfa and M.A. Hutterli, Field Anal. Chem. Technol., 5 (2001) 2-12.

[18] A. Pretto, M.R. Milani and A.A. Cardoso, J. Environ. Monit., 2 (2000) 566-570.

[19] K. Toda, W. Tokunaga, Y. Gushiken, K. Hirota, T. Nose, D. Suda, J. Nagai and S.-I. Ohira, Journal of Environmental Monitoring, 14 (2012) 1462-1472.

[20] A. Allouch, M. Guglielmino, P. Bernhardt, C. Serra and S. Le Calvé, Sensors and Actuators B: Chemical, 181 (2013 and references therein) 551-558.

[21] S. Le Calvé, W. Zheng, J.L. Ponche and P. Bernhardt, Device and method for determining the concentration of a compound in an aqueous or gaseous phase, patent WO2010142908. 2012: France. p. 12-16.

[22] Y.T. Shah, B.G. Kelkar, S.P. Godpole and W.-D. Deckwer, AICHE Journal, 28 (1982) 353-379.

[23] D. Barnea, Int. J. of Multiphase Flow, 13 (1987) 1-12.

[24] L Galbiati and P. Andreini, Int. Commun. Heat Mass Transf., 21 (1994) 461-468.

[25] Y. Taitel and A.E. Dulkler, AIChE J., 22 (1976) 47-55.

[26] M.K. Akbar, D.A. Plummer and S.M. Ghiaasiaan, Int. J. Multiph. Flow 29 (2003) 855-865.

[27] S. Waelchli and R.P. Von Rohr, Int. J. Multiph. Flow, 32 (2006) 791-806.

[28] M. Ishii and T. Hibiki, Thermo-fluid dynamics of two-phase flow. 2 nd edition. Sringer. ISBN 9781-4419-7984-1. 2006.

[29] E.V. Rebrov, Theoretical Foundations of Chemical Engineering, 44 (2000) 355-367.

[30] K.A. Tripplett, S.M. Ghiaasiaan, S.I. Abdel-Khalik and D.L. Sadowski, Int. J. Multiph. Flow, 25 (1999) 377-394.

[31] P.M.-Y. Chung and M. Kawaji, Int. J. Multiph. Flow, 30 (2004) 735-761.

[32] M. Guglielmino, A. Allouch, C. Serra and S. Le Calvé, Sensors and Actuators B: Chemical, 243 (2017) 963-970.

[33] U. Eisner and J. Kuthan, Chemical Reviews, 72 (1972) 1-42.

[34] C. Marchand, B. Bulliot, S. Le Calvé and Ph. Mirabel, Atmos. Environ., 40 (2006) 1336-1345.

[35] L. Allou, L. El Maimouni and S. Le Calvé, Atmos. Environ., 45 (2011) 2991-2998.

[36] P.M-Y. Chung and M. Kawaji, International Journal of Multiphase Flow, 30 (2004) 735-761.

[37] A. Sur and D. Liu, Int. J. Therm. Sci, 53 (2012) 18-34.

[38] J. Li, P.K. Dasgupta and W. Luke, Anal. Chim. Acta, 531 (2005) 51-68.

[39] G. Bertoni, C. Ciuchini, V. Di Palo and M. Possanzini, Chromatographia, 61 (2005) 385-389. 